\title{
Infection Rate of Babesia spp. Sporokinetes in Engorged Boophilus microplus from an Area of Enzootic Stability in the State of Minas Gerais, Brazil
}

\author{
Maria G Quintão-Silva, Múcio FB Ribeiro*/+
}

Universidade de Alfenas, Alfenas, MG, Brasil *Departamento de Parasitologia, ICB, Universidade Federal de Minas Gerais, Caixa Postal 486, 31270-910 Belo Horizonte, MG, Brasil

The infection rates of Babesia sporokinetes in engorged Boophilus microplus were evaluated during a 2-year period in a dairy farm located in an area of enzootic stability. Every 14 days engorged females were collected from calves and from adult animals. Ticks were incubated at $27 \pm 0.5^{\circ} \mathrm{C}$ and $80-90 \%$ relative humidity and Babesia infection rates were determined by microscopic examination of Giemsa-stained hemolymph smears. After 52 collections, 2105 ticks were obtained, from which 982 were collected from calves and 1123 from cows. The total Babesia infection rate was $10 \%$, however the incidence was higher $(p<0.05)$ in ticks collected from calves $(17.5 \%)$ than in those collected from cows (3.6\%). Females collected from cows showed the highest infection rates in January, March, and August, and absence of infection in April and May. Ticks feeding on calves were infected throughout the experimental period. The infection rates of engorged females collected from naturally infected calves that were artificially infested with Babesia-free-larvae of B. microplus gradually decreased until the calves were four months old. No differences were observed among infection rates of ticks collected from calves maintained under natural conditions.

Key words: Babesia sp. - tick - sporokinetes - Boophilus microplus - Minas Gerais - Brazil

Babesiosis is a disease caused by intraerythrocytic protozoan parasites of the genus Babesia, which infect domestic and wild animals, transmitted by ixodid ticks. In Latin America two species, Babesia bovis and B. bigemina, infect cattle, both transmitted by the one-host tick Boophilus microplus (Alonso et al. 1992).

The state of Minas Gerais, Brazil, has an area of 588,386 $\mathrm{km}^{2}$ and the population of cattle is estimated in 20,082,067 heads, corresponding to $12.2 \%$ of the national heard (Anuário Estatístico de Minas Gerais 2002). In the state, bovine babesiosis has been a limiting disease for the cattle industry (Leite \& Lima 1982, Ribeiro et al. 1983), although the region has been considered an area of enzootic stability (Patarroyo et al. 1987).

The main factors interfering with transmission of Babesia are the tick parasitic load on cattle and the infection rate in the ticks (Friedhoff \& Smith 1981). Several reports on seasonal variation of $B$. microplus ticks have been published and it is known that in Minas Gerais four generations occur per year with infestations throughout the year (Magalhães 1989, Lima et al. 2000). However, little is known about infection rates of Babesia spp. in $B$. microplus and the studies have been carried out under laboratory conditions.

Financial support: Fundação de Amparo à Pesquisa do Estado de Minas Gerais

${ }^{+}$Corresponding author. Fax: +55-31-3499.2970. E-mail: muciobr@mono.icb.ufmg.br

Received 5 June 2003

Accepted 14 October 2003
The implementation of strategic control programs against $B$. microplus ticks associated to new management measures in raising calves have contributed to the establishment of areas of enzootic instability in some farms, increasing economic losses due to clinical cases of babesiosis. As a consequence, considerable efforts have been made to a better understanding of epidemiological aspects of babesiosis. In addition to estimation of cattle serum reactivity to $B$. bigemina and $B$. bovis, the knowledge of infestation levels and the infection rates in the ticks are essential information for a comprehensive epidemiological study on bovine babesiosis (Alonso et al. 1992).

The present study had the objective to determine the infection rates of Babesia spp. in B. microplus ticks infesting calves and adult cattle, during the dry and the rainy seasons in a dairy farm located in an area of enzootic stability.

\section{MATERIALS AND METHODS}

Study site - The study was carried out on a dairybreeding farm, in the municipality of Pedro Leopoldo $\left(19^{\circ} 37^{\prime} \mathrm{S}, 42^{\circ} 02^{\prime} \mathrm{W}\right.$, altitude $\left.882 \mathrm{~m}\right)$, state of Minas Gerais, over a 2-year period, from March 1999 to February 2001. The region has a distinct dry season (winter) from April to September and a rainy season (summer) from October to March.

Animals - Crossbreed cattle (7/8 Holstein x Zebu) were kept on a natural pasture comprised of "capim jaraguá" (Hyparrhenia rufa), "capim gordura" (Melinis minutiflora), and "capim braquiária" (Brachiaria decumbens). In the farm, the newborn calves were kept with their respective mothers for two days and then were transferred to calf hutches where they stayed up to 30 days of age and then they were raised on natural pastures. The calves 
received 41 of milk daily and balanced ration ad libitum.

The animals were divided into two groups. Group I had 24 female calves, less than eight months of age. At the age of eight months, other newborn calves replaced these calves. Group II had 24 animals older than 24 months. Each group was subdivided into four subgroups with six animals each.

Every 14 days one subgroup in each group was sequentially treated with an organophosphorus acaricide, coumaphos (Assuntol, Bayer), resulting in the treatment of all subgroups every 56 days. Each animal was dipped, using a hand sprayer, with approximately 51 of $0.05 \%$ coumaphos, freshly prepared each time. The acaricide treatment was used to prevent development of injurious levels of tick infestation on the animals.

Other four newborn calves were monitored weekly by blood smears. As soon as infections of Babesia spp. were detected in blood smears, the animals were treated with acaricide and kept isolated. Every seven days these animals were individually infested with 2000 B. microplus larvae, which were originated from a Babesia-free colony. Engorged females were collected weekly from these calves.

Tick collection - Every 14 days, the animals in groups I and II were gathered, always between 8 and 10 a.m., and all B. microplus engorged females larger than $4.5 \mathrm{~mm}$ were collected. Ticks were individually placed into glass tubes and identified with the number of the animal from which they had been collected.

From each collection, 48 engorged females were selected ( 24 from calves and 24 from cows). Ticks were individually placed in polystyrene plates and incubated at $27 \pm 0.5^{\circ} \mathrm{C}$ and $80-90 \%$ relative humidity. Females collected from calves that had been infested with Babesiafree larvae were submitted to the same procedures.

Hemolymph examination - Smears were prepared from a section at a distal region of one leg of engorged females, after an 8-day incubation period. Smears were made on glass slides, stained with Giemsa, and examined microscopically under immersion. The whole smear was examined considering the following parameters: (a) monthly infection rates (IR): defined as the percentage of Babesia spp. positive ticks related to the total number of ticks examined per month; (b) infection intensity (II): defined as the number of Babesia spp. sporokinetes counted in each hemolymph smear, divided by the number of microscopic fields examined per smear. Each number for IR represents the mean number of monthly observations.

Statistical analysis - The data are presented combining the values of the corresponding months during the two years of study, using analysis of variance (ANOVA); the infection rates of ticks were compared by the chi-square test.

\section{RESULTS}

In some occasions during the experimental period it was not possible to obtain the desirable number of 48 ticks on all animals in the two groups. Some engorged females died during the BOD incubation period, previously to preparation of hemolymph smears.

After 52 collections, 2106 B. microplus engorged females were obtained, from which $983(46.7 \%)$ were collected from calves and $1123(53.3 \%)$ were collected from cows. Hemolymph smears were prepared from all females, but the amount of fluid extracted from them was variable. The mean number of microscopic fields examined per smear was $147 \pm 87$ (ranging from 5 to 1175 ), and no significant differences were seen between smears made from females collected from calves and females collected from cows.

The total Babesia spp. infection rate of B. microplus engorged females was $10.1 \%$. The infection rate of females collected from calves $(17.5 \%)$ was significantly higher $(\mathrm{p}<0.05)$ than that observed in females collected from cows $(3.6 \%)$. The probability to find a Babesia-infected engorged female feeding on a calf was five times greater than that to find an infected female feeding on a cow.

The monthly variation of Babesia infection rate in $B$. microplus is presented in Fig. 1. The mean incidence of Babesia sporokinetes in the tick vector in the calf group was constantly higher than that in the cow group. The engorged females feeding on calves were infected throughout the experimental period, with infection rates ranging from 9.4 to $31.1 \%$. The lowest infection rate was observed in March and the highest in November. It was observed that females collected from cows showed the highest infection rates in January (6.9\%), March (8.5\%), and October (9.4\%), with absence of infection in April and May (Fig. 1).

The studied region is characterized by two defined seasons: a dry season from April to September and a rainy season from October to March. The mean rainfall was $19.5 \mathrm{~mm}^{3}$ (ranging from 0 to $56.7 \mathrm{~mm}^{3}$ ) during the dry season, and $215.3 \mathrm{~mm}^{3}$ (ranging from 69.8 to $469.5 \mathrm{~mm}^{3}$ ) during the rainy season (Fig. 1).

Babesia spp. infection rates in engorged females collected from cows during the rainy season were significantly higher $(\mathrm{p}<0.05)$ than those observed during the dry season. In contrast, infection rates in engorged females collected from calves showed no significant variations between the two seasons (Fig. 2).

The mean number of Babesia sporokinetes per microscopic field in engorged females collected from calves (3.1) was significantly higher $(\mathrm{p}<0.05)$ than that obtained in females collected from cows $(0.5)$.

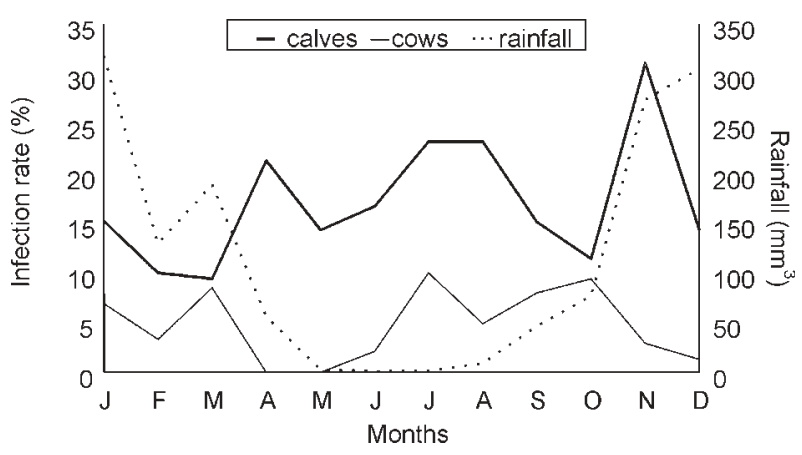

Fig. 1: Babesia spp. infection rate (\%) in Boophilus microplus engorged females collected from calves and cows in relation to rainfall, from March 1999 to February 2001, Pedro Leopoldo, Minas Gerais, Brazil. 


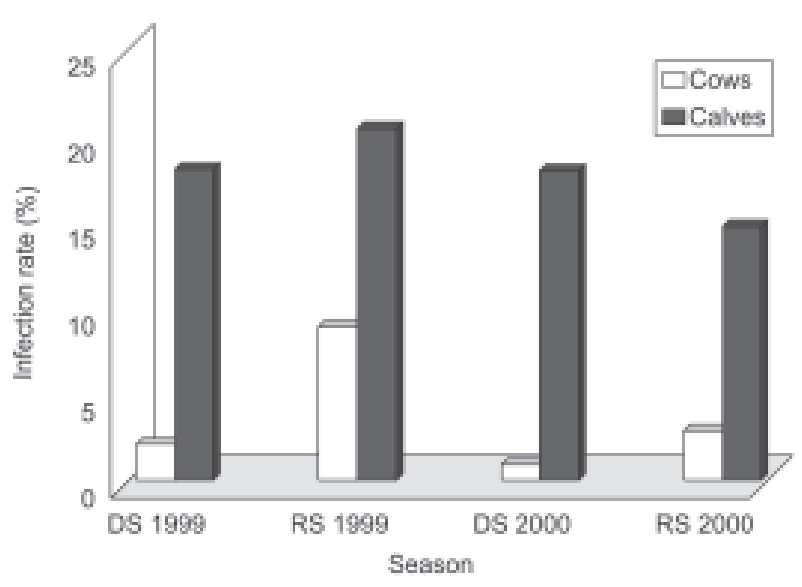

Fig. 2: Babesia spp. infection rate (\%) in Boophilus microplus engorged females collected from calves and cows, during dry seasons (DS) and rainy seasons (RS), Pedro Leopoldo, Minas Gerais, Brazil.

The infection rates observed in engorged females collected from the four naturally infected calves, maintained in isolation and artificially infested with Babesia-free-larvae are shown in the Table. The infection rate of engorged females collected when calves were two months old was $13.7 \%$. This value showed a gradual decrease until the age of four months; and when calves were five months old the infection rate of engorged females was only $0.7 \%$.

Infection rates of engorged females collected from oneto five-months-old calves, maintained under natural conditions, ranged from 9.7 to $17.8 \%$, with no significant differences $(\mathrm{p}<0.05)$ (Table).

\section{DISCUSSION}

The farm where the experiment was carried out is considered an area of enzootic stability, where calves usually become infected with $B$. bigemina and $B$. bovis during their first weeks of life. There is a relationship between age and resistance to Babesia infections (Callow et al. 1976, Mahoney 1979); however, if the population of B. microplus increases clinical cases of babesiosis may occur in calves. Under these circumstances, there is a need to adopt programs of acaricide dipping to prevent emergence of disease. The acaricide-dipping protocol adopted for calves and cows was effective in avoiding high infestation levels of $B$. microplus. The 56-day-interval between treatments was sufficient for re-infestations, since coumaphos has a residual effect of three days and the parasitic stage of $B$. microplus ticks requires a developmental period of 23 days (Magalhães 1989).

Riek (1964, 1966), describing the life cycle of $B$. bigemina and $B$. bovis in their tick vector B. microplus, suggest that the distinctive morphological characteristics of the kinetes in the ticks could be of value in epidemiological studies. However, differentiation between $B a$ besia species based only on morphological aspects of sporokinetes has been questionable (Guglielmone et al. 1996). For this reason, sporokinetes were not differentiated in the present study.

It was observed, throughout the experimental period, that engorged females collected from calves had Babesia spp. infection rates significantly higher than those collected from cows. It is known that engorging females are the only stage of $B$. microplus ticks that becomes infected with Babesia spp., and only if they feed on cattle with parasitemia during the last 16 to $24 \mathrm{~h}$ before detachment (Callow \& Hoyte 1961, Friedhoff \& Smith 1981). Most of the parasites imbibed by the tick die within the tick gut. Only the gamonts survive and differentiate into ray bodies, which are diploid and start immediately cell divisions. This process results in the formation of haploid gametes (Mackenstedt et al. 1995), which will initiate a sexual process in the vector leading to the formation of sporokinetes. Thus, the key to understand the process of infection of engorged females has to do with formation of gamonts in the vertebrate host.

In experimental infections the maximum infectivity of ticks occur during the initial phase of parasitemia, although the animals maintain the capacity to infect ticks with $B$. bigemina for four to seven weeks, and with $B$. bovis for one year (Mahoney 1969). After the primo infection, calves living in endemic areas, suffer successive inoculations of Babesia sporozoites due to infestations of naturally infected ticks, and consequently present high levels of infectivity for engorging females. However, adult animals, even when exposed to constant inoculations of Babesia sporozoites by ticks, present low parasitemia and low transmission rates to the engorging females. This fact suggests that the low infection rates of females collected from adults are related to the development of immunity against Babesia stages in the host, including the

\section{TABLE}

Infection rate of Babesia spp. in Boophilus microplus engorged females collected from infected calves maintained isolated or under natural conditions in an endemic area in the state of Minas Gerais, Brazil, 1999 to 2001

\begin{tabular}{|c|c|c|c|c|c|c|}
\hline \multirow[b]{2}{*}{$\begin{array}{l}\text { Age } \\
\text { (months) }\end{array}$} & \multicolumn{3}{|c|}{ Isolated $(n=4)$} & \multicolumn{3}{|c|}{ Under natural conditions $(n=73)$} \\
\hline & $\begin{array}{c}\text { Examined } \\
\text { engorged females }\end{array}$ & $\begin{array}{c}\text { Positive } \\
\text { engorged females }\end{array}$ & $\begin{array}{c}\% \\
\text { positive }\end{array}$ & $\begin{array}{c}\text { Examined } \\
\text { engorged females }\end{array}$ & $\begin{array}{c}\text { Positive } \\
\text { engorged females }\end{array}$ & $\begin{array}{c}\% \\
\text { positive }\end{array}$ \\
\hline 1 & - & - & - & 129 & 15 & 11.6 \\
\hline 2 & 241 & 33 & 13.7 & 145 & 14 & 9.7 \\
\hline 3 & 451 & 47 & 10.4 & 162 & 25 & 15.4 \\
\hline 4 & 280 & 26 & 9.3 & 129 & 23 & 17.8 \\
\hline 5 & 142 & 1 & 0.7 & 91 & 14 & 15.4 \\
\hline$>6$ & - & - & - & 106 & 27 & 25.4 \\
\hline Total & 1114 & 107 & 9.6 & 762 & 118 & 15.5 \\
\hline
\end{tabular}


gamonts. Therefore, after blood suckling, antibodies in the tick gut, limiting the continuation of the life cycle, neutralize the gamonts. Development of specific antibodies against the sexual stages has been described in infections by Plasmodium falciparum and P. vivax. These antibodies interfere in the parasite transmission by neutralizing gametes in the gut of mosquitoes ( $\mathrm{Lal}$ et al. 2001). However, it is possible that anti-gamont antibodies induced in the bovine host are not able to neutralize all the gamonts due to an escaping mechanism created by the parasite. Evidence for that is the fact that some gamonts are reported to be surrounded by an erythrocytic membrane while within the lumen of the tick midgut (Friedhoff 1990) and thus may never be directly exposed to antibodies.

After recovering from patent disease, calves may develop sub clinical infections that last for several months (Johnston et al. 1978). However, when the calves kept isolated after primo infection were infested with Babesiafree ticks the infection rate of engorged females was higher at the beginning of host infections (Table), with progressive decrease, in accordance with observations reported by Mahoney (1969). The calves living in the endemic area, with constant inoculations of sporozoites by ticks, remained infective to engorging females during the six months of observation. These results suggest the need of an ongoing life cycle in the tick for gamont formation in the host. After several cycles of multiplication in the vertebrate host, the parasite probably losses the capacity to form gamonts, with consequent reduction of its ability to infect $B$. microplus ticks.

The monthly variation of sporokinete incidence in ticks collected from cows was higher during the rainy season, in both years of observation. This finding ratifies seasonality for Babesia spp. infected ticks, which would lead to greater chances of transmission during the rainy season.

Babesia inoculation rate is directly related to the intensity of infestation and to the infection rate. In the state of Minas Gerais, the rainfall appeared to be the climatic factor that most influenced the seasonal variation in intensity of infestation of B. microplus (Lima et al. 2000). During the dry season, when rainfall and temperatures were low, there was a sharp reduction in B. microplus infestation. The onset of the rainy season produced a rise in infestation levels, which remained relatively high until February. Thus, the increased infestation levels lead to an increased Babesia inoculation rate in the animals, allowing the development of gamonts and, consequently, an increased infection rate in engorged females.

During the dry season, decreases in temperature may interfere with the Babesia biological cycle in the tick. Low temperatures may completely inhibit alimentary and transovarial Babesia infections in B. microplus engorged females (Rieck 1964). Despite the occurrence of $B$. microplus infestations during cold periods, larvae may show reduction in Babesia infection rates and, therefore, the possibility to induce formation of gamonts is reduced in the host. In contrast, the young animals that have not yet developed immunity against gamonts are able to maintain high levels of gamont formation and high infection rates for engorging females, even though they are inoculated with fewer sporozoites.

\section{REFERENCES}

Alonso M, Arellano-Sota C, Cereser VH, Cordoves CO, Guglielmone AA, Kessler R, Mangold AJ, Nari A, Patarroyo JH, Solari MA, Veja CA, Vizcaino O, Camus CA 1992. Epidemiology of bovine anaplasmosis and babesiosis in Latin America and the Caribbean. Vet Sci Tech Off Int Epiz 11: 713-733.

Anuário Estatístico De Minas Gerais 2002. 2000-2001, v. 9 , Fundação João Pinheiro, Belo Horizonte, p. 44.

Callow LL, Hoyte HMD 1961. Transmission experiments using Babesia bigemina, Theileria mutans, Borrelia sp., and the tick Boophilus microplus. Aust Vet J 37: 381-390.

Callow LL, Emmerson FR, Parker RJ, Knott SG 1976. Infection rates and outbreaks of disease due to Babesia argentina in unvaccinated cattle on 5 beef proprieties in South-eastern. Queensland Aust Vet J 52: 446-450.

Friedhoff KT 1990. Interaction between parasite and tick vector. Int J Parasitol 20: 525-535.

Friedhoff KT, Smith RD 1981. Transmission of Babesia by ticks. In M Ristc, JP Kreier (eds), Babesioses, Academic Press, San Diego, p. 267-321.

Guglielmone AA, Gaido AB, Mangold AJ 1996. Light microscopy diagnosis of Babesia bovis and Babesia bigemina kinetes in the haemolymph of artificially infected Boophilus microplus engorged female ticks. Vet Parasitol 61: 15-20.

Johnston LAY, Leatch G, Jones PN 1978. The duration of latent infection and functional immunity in Droughtmaster and Hereford cattle following natural infection with Babesia argentina and Babesia bigemina. Aust Vet J 54: 14-18.

Lal AA, Patterson PS, Sacci JB, Vaughan JA, Collins WE, Wirtz RA, Azad AB 2001. Anti-mosquito midgut antibodies block development of Plasmodium falciparum and Plasmodium vivax in multiple species of Anopheles mosquitoes and reduce vector fecundity and survivorship. Proc Natl Acad Sci USA 98: 5228-5233.

Leite RC, Lima JD 1982. Fatores sanitários que influenciam na criação de bezerros. Arq Esc Vet UFMG 34: 485-492.

Lima WS, Ribeiro MFB, Guimarães MP 2000. Seasonal variation of Boophilus microplus (Canestrini, 1887) (Acari: Ixodidae) in cattle in Minas Gerais State, Brazil. Tropic Anim Health Prod 32: 375-380.

Mackenstedt U, Gauer M, Fuchs P, Zapf F, Schein E, Mehlhorn H 1995. DNA measurements reveal differences in the life cycles of Babesia bigemina and B. canis, two typical members of the genus Babesia. Parasitol Res 81: 595-604.

Magalhães FEP 1989. Aspectos Biológicos, Ecológicos e de Controle do Boophilus microplus (Canestrini,1887) no Município de Pedro Leopoldo, MG, MSc Thesis, Instituto de Ciências Biológicas, UFMG, Belo Horizonte, 115 pp.

Mahoney DF 1969. Bovine babesiosis: a study of factors concerned in transmission. Ann Trop Med Parasitol 6: 1-14.

Mahoney DF 1979. Babesia of domestic animals. In JP Kreier, Parasitic Protozoa, Academic Press, San Diego, p. 1-52.

Patarroyo JH, Ribeiro MFB, Santos JL, Faria JE 1987. Epidemiologia da babesiose bovina no Estado de Minas Gerais. I - Prevalência de anticorpos fluorescentes na Zona da Mata, MG. Arq Bras Med Vet Zootec 39: 423-429.

Ribeiro MFB, Patarroyo JH, Santos JL, Faria JE 1983. Inquérito de opinião com criadores da Zona da Mata do Estado de Minas Gerais. I - Alguns fatores associados com mortalidade de bezerros. Arq Bras Med Vet Zootec 35: 547-556.

Riek RF 1964. The life cycle of Babesia bigemina (Smith \& Kilborne, 1893) in the vector Boophilus microplus (Canestrini, 1887). Aust J Agr Res 15: 802-821.

Riek RF 1966. The life cycle of Babesia argentina (Ligniéres, 1903) (Sporozoa: Piroplasmidea) in the tick vector Boophilus microplus (Canestrini, 1887). Aust J Agric Res 17: 247-254. 